\title{
Rapid Quantification of Functional Carbohydrates in Food Products
}

\author{
Annabelle Le Parc ${ }^{1}$, Hyeyoung Lee ${ }^{1,2}$, Kevin Chen ${ }^{1}$, Daniela Barile ${ }^{1,2^{*}}$ \\ ${ }^{1}$ Department of Food Science and Technology, University of California, Davis, USA; ${ }^{2}$ Foods for Health Institute, University of Cali- \\ fornia, Davis, USA. \\ Email: "dbarile@ucdavis.edu
}

Received December $2^{\text {nd }}, 2013$; revised January $2^{\text {nd }}, 2014$; accepted January $9^{\text {th }}, 2014$

Copyright (C) 2014 Annabelle Le Parc et al. This is an open access article distributed under the Creative Commons Attribution License, which permits unrestricted use, distribution, and reproduction in any medium, provided the original work is properly cited. In accordance of the Creative Commons Attribution License all Copyrights (C) 2014 are reserved for SCIRP and the owner of the intellectual property Annabelle Le Parc et al. All Copyright (C) 2014 are guarded by law and by SCIRP as a guardian.

\section{ABSTRACT}

Current research on milk bioactive components, including complex oligosaccharides, stimulated development of novel milk-based ingredients; this in turn sparked the development of methods that are simultaneously simple and sensitive. Oligosaccharides and glycoproteins present interesting health benefits, including antibacterial and antiviral effects, stimulation of the immune system, and participation in the establishment of a balanced gut microbiome in infants. This work describes the application of a simple and rapid method-Total Carbohydrate Assay - to the determination of functional carbohydrate content in various dairy-based functional products. The miniaturization and optimization of the carbohydrate quantification on microplates afforded good repeatability and sensitivity. The optimized method consumed only minimal amounts of reagents and samples, and carbohydrates were detected in the range from 0 - $20 \mu$ g. This assay was successfully applied to determine the content of complicated oligosaccharide mixtures and $\mathrm{N}$-glycans in dairy-derived products. Several complementary analytical techniques were applied to confirm the results. This method is faster and far less expensive than mass spectrometry and it gives a general picture of complex carbohydrate concentrations for instances in which detailed data are not required as needed for research in discrete differences among various biological samples. The ability to quantify glycans in novel food products will provide a unique understanding of the potential of these novel ingredients for use by the food industry.

\section{KEYWORDS}

\section{Carbohydrates; Milk; Colorimetric Method; Microplate; Mass Spectrometry}

\section{Introduction}

Functional foods are identified as crucial elements for the development of the food industry and research. It is seen as a priority to support the ambitions of the food industry in this market segment. Milk contains a variety of components, including proteins, peptides, lipids, carbohydrates and salts, which are essential for nourishing and protecting the infant. In human milk, carbohydrates are one of the most important components present in high concentration [1]. The main carbohydrates in milk are lactose, oligosaccharides, monosaccharides and $N$-glycans. Oligosaccharides are some of the most important

\footnotetext{
*Corresponding author.
}

bioactive components in milk, but they are still undercharacterized due to their overall complexity. Oligosaccharides are chains of monosaccharides between 3 and 20 sugar units in length, and they can have diverse and complicated structures. In particular, the structural elements fucose and sialic acid appear to be crucial to the ability of oligosaccharides to act as bioactive components. Five monosaccharides (glucose, galactose, $N$-acetyl-glucosamine, fucose and sialic acid) are linked in various ways through at least 12 alpha- and beta-glycosidic linkages. Oligosaccharides and glycoproteins present interesting health benefits, including antibacterial and antiviral effects, stimulation of the immune system, and participation in the establishment of a balanced gut microbi- 
ome in infants [2-4]. Due to limited availability of oligosaccharides and $N$-glycans from human milk, ongoing research is investigating alternative sources of complex carbohydrates for in vitro and clinical studies.

This novel branch of research on the bioactive milk glycans requires methods that can rapidly determine the abundance of carbohydrates in milk products in absence of commercial standards. Milk glycans are particularly challenging to analyze due to their structural complexities, especially those of oligosaccharides and glycoproteins. In contrast to proteins, carbohydrates do not have a chromophore and they cannot be detected by common spectroscopic methods (including UV detection). Liquid chromatography coupled to mass spectrometry, highperformance liquid chromatography and high-performance anion liquid chromatography with a pulsed amperometric detection is the method commonly used to quantify complex carbohydrates [5-8]. These techniques are sensitive and accurate, but they require significant investments to acquire complex instruments and highlytrained personnel to perform analysis.

This work describes the application of a simple and rapid method to quantify complex carbohydrates, i.e. those containing three or more different monosaccharide units. Current colorimetric methods include the phenolsulfuric acid method and other techniques that use anthrone, orcinol, or resorcinol [9-11]. However, the phenol-sulfuric acid method works well only for carbohydrates that are made of the same repeating units-homopolymers made of the same monosaccharide type-but it does not work well for complex carbohydrates-heteropolymers made of different monosaccharide units. Other techniques based on HPLC require the use of commercial standards, which unfortunately are not available for all the carbohydrates found in milk and foods due to their structural diversity and complexity. Based on the wellknown phenol-sulfuric acid method, a simple kit (Total Carbohydrate Assay) was developed and is now commercially available. It can achieve good sensitivity and repeatability. The goal of this work was to quantify functional carbohydrates in dairy-based functional products while improving sensitivity and repeatability of the kit using a microplate format. The method was optimized for detection of the carbohydrate content of more complex samples, including free oligosaccharides and $\mathrm{N}$-glycans released from proteins.

\section{Materials and Methods}

\subsection{Materials}

The Total Carbohydrate Assay from Biovision (Milpitas, CA, USA), consisted of the following components: 25 $\mathrm{mL}$ of Assay Buffer, $3 \mathrm{~mL}$ of Developer (chemical composition unknown), and $0.2 \mathrm{~mL}$ of standard solution
(D-glucose, $2 \mathrm{mg} / \mathrm{mL}$ ). All components are stable at room temperature and can be stored for 2 months at $4^{\circ} \mathrm{C}$. Additional materials required for the assays included concentrated sulfuric acid (98\%) from Sigma-Aldrich (St. Louis, MO, USA), 96-well clear plates with flat bottoms and a spectrophotometer (SpectraMax Plus384 Absorbance Microplate Reader, Molecular Devices, Sunnyvale, CA, USA). Monosaccharides tested included: L-fucose, D-glucose, D-galactose and D-mannose from Sigma Aldrich. Test-Combination from Lactose/D-Glucose kit from R-Biopharm (Darmstadt, Germany) included 600 $\mathrm{mg}$ of lyophilizate, consisting of citrate buffer $\mathrm{pH}$ 6.6; $1.7 \mathrm{~mL}$ suspension $\beta$-galactosidase; $5 \mathrm{~g}$ of powder mixture consisting of triethanolamine buffer $\mathrm{pH}$ 7.6; $70 \mathrm{mg}$ of nicotinamide-adenine dinucleotide phosphate (NADP), $170 \mathrm{mg}$ of adenosine-5'-triphosphate (ATP); magnesium sulfate; $1.4 \mathrm{~mL}$ suspension consisting of hexokinase (HK); and glucose-6-phosphate dehydrogenase (G6PDH). Two bovine oligosaccharides-enriched (BMOs) products were supplied by a local dairy manufacturer, and one sample of lactoferrin that contained complex glycans, was purified from human milk.

\subsection{Optimization of Total Carbohydrate Assay}

The Total Carbohydrate Assay used concentrated sulfuric acid to hydrolyze glycans to monomers, which were converted to furfural or hydroxyfurfural. The furfural or hydroxyfurfural reacted with the developer to form a chromogen that was quantified using a spectrophotometer. The glucose standard curve provided a linear function to calculate the concentration of carbohydrates in each sample. To create the standard curve, $0,2,4,6,8$ and $10 \mu \mathrm{l}$ of glucose standard $(2 \mathrm{mg} / \mathrm{mL})$ was added into a series of wells in a 96-well microplate. This generated $0,4,8,12,16$ and $20 \mu \mathrm{g} /$ well of glucose standard. For some experiments, other amounts of glucose were tested: $0,1,2,3,4$ and $5 \mu \mathrm{g} /$ well, or 0, 2, 4, 6, 8 and $10 \mu \mathrm{g} /$ well. The volume of each sample was adjusted to $30 \mu \mathrm{l}$ per well with water. For this work, several doses of samples were tested to ensure that the readings were within the standard curve range. After both the samples and the glucose standard were added to the microplate in appropriate amounts, $150 \mu \mathrm{l}$ of concentrated sulfuric acid (98\%) were added to each well. The samples were mixed on a shaker for $\sim 1 \mathrm{~min}$ and then incubated at $85^{\circ} \mathrm{C}$ for 15 min. After incubation, $30 \mu \mathrm{l}$ of Developer was added to each well. The samples were again mixed on the shaker for $5 \mathrm{~min}$. The microplate was placed in the spectrophotometer and the OD was measured at $490 \mathrm{~nm}$. ODs were read from 10 to $30 \mathrm{~min}$ in order to see whether the incubation time in the microplate reader would affect the measurements. The sample OD was applied to the glucose standard curve linear function to calculate the quantity of carbohydrate in the sample. 


\subsection{Lactose Quantification by Enzymatic Kit}

Lactose was quantified using an enzymatic kit, the "lactose/D-glucose" that utilized UV method. The enzyme $\beta$-galactosidase hydrolyzed lactose to $\mathrm{D}$-glucose and $\mathrm{D}$-galactose at $\mathrm{pH}$ 6.6. D-glucose was then phosphorylated at $\mathrm{pH} 7.6$ by $\mathrm{HK}$, in the presence of ATP, to D-glucose-6-phosphate (G-6-P) with the simultaneous formation of adenosine-5'-diphosphate (ADP). In the presence of NADP, G-6-P was oxidized by the enzyme G6P-DH to D-gluconate-6-phosphate with the formation of reduced NADPH. The amount of NADPH formed was stoichiometric to the amount of the lactose and D-glucose. NADPH was measured by absorbance at $340 \mathrm{~nm}$. The amount of lactose was calculated using the difference between D-glucose concentration with and without hydrolysis with $\beta$-galactosidase.

\subsection{Monosaccharides Quantification by HPLC}

The concentration of glucose and galactose was analyzed using an HP 1100 Series HPLC (Hewlett-Packard, Palo Alto, CA, USA) equipped with an autoinjector, quarternary pump, column heater, a refractive index detector, and an Agilent ChemStation (Agilent Technologies, Santa Clara, CA, USA) for data collection and manipulation. BioRad HPX-87H column (BioRad, Hercules, CA, USA) was used and heated at $55^{\circ} \mathrm{C}$. As a mobile phase, $0.01 \mathrm{~N} \mathrm{H}_{2} \mathrm{SO}_{4}$ was used, and the flow rate was $0.6 \mathrm{~mL} /$ $\min$.

\subsection{Sample Preparation}

The oligosaccharide-rich powders were dissolved in water $(1 \%, w / v)$. A $100-\mu \mathrm{L}$ aliquot of sample was loaded on a graphitized carbon cartridge (GCC-SPE, $150 \mathrm{mg}$ carbon, 4-mL tube capacity, Alltech, Deerfield, IL, USA) that was conditioned with three volumes of $80 \%$ acetonetrile, $0.1 \%$ trifluoroacetic acid (TFA) in water $(\mathrm{v} / \mathrm{v})$ and washed by three volumes of water. The GCC cartridge was washed with three volumes of water, and the oligosaccharides were eluted with three volumes of $40 \%$ acetonitrile, $0.1 \%$ TFA in water $(\mathrm{v} / \mathrm{v})$. The BMO fraction was dried overnight by vacuum centrifugation. BMO samples were rehydrated in $1 \mathrm{~mL}$ of water and diluted one hundred fold prior to mass spectrometry analysis.

Lactoferrin was purified from donor human milk by affinity chromatography as described by Barboza et al., (2012) [12]. The purity of the protein was monitored by sodium dodecyl sulfate gel electrophoresis (data not shown).

\subsection{Compositional Analysis by Q-TOF/Mass Spectrometry}

The BMO samples were analyzed using the Agilent 6520 accurate-mass quadrupole-time-of-flight (Q-TOF) LC/MS with a microfluidic nano-electrospray chip (Agilent Technologies). The BMOs were separated using a HPLC-Chip with a 40-nL enrichment column and a 43 $\mathrm{mm} \times 75 \mu \mathrm{m}$ analytical column, both packed with $5-\mu \mathrm{m}$ porous graphitized carbon. The system was composed of a capillary and nanoflow pump, and both used binary solvents consisting of solvent A ( $3 \%$ acetonitrile (ACN), $0.1 \%$ formic acid in water $(\mathrm{v} / \mathrm{v}))$ and solvent B $(90 \%$ ACN, $0.1 \%$ formic acid in water $(\mathrm{v} / \mathrm{v}))$. Two $\mu \mathrm{L}$ of sample were loaded with solvent $A$ at a capillary pump flow rate of $4 \mu \mathrm{L} / \mathrm{min}$. The BMO separation was performed on a 65-min gradient delivered by the nanopump at a flow rate of $0.3 \mu \mathrm{L} / \mathrm{min}$. The 65 -min gradient followed this program: 0\% B (0.0 - $2.5 \mathrm{~min})$; 0 to $16 \% \mathrm{~B}$ (2.5 - 20.0 min); $16 \%$ to $44 \%$ B (20.0 - $30.0 \mathrm{~min}) ; 44 \%$ to $100 \%$ B (30.0 - $35.0 \mathrm{~min})$ and $100 \% \mathrm{~B}(35.0$ - $45.0 \mathrm{~min})$. The gradient was followed by equilibration at $0 \%$ B (45.0 $65.0 \mathrm{~min}$ ). Data were acquired within the mass range of $\mathrm{m} / \mathrm{z} 450$ - 3000 in the positive ionization mode with an acquisition rate of 2.01 spectra/s. An internal calibrant ion of $\mathrm{m} / \mathrm{z} 922.010$ from tuning mix (ESI-TOF Tuning Mix G1969-85000, Agilent Technologies) was used for continual mass calibration. Acquisition was controlled by MassHunter Workstation Data Acquisition software (Agilent Technologies). Compounds were identified with MassHunter Qualitative Analysis software (version B.04.00 SP2, Agilent Technologies). The compounds were extracted and matched to a BMO library [13] using the reproducible retention times and the accurate masses of each compound. The relative abundance of BMOs was determined.

\section{Results and Discussion}

\subsection{Linearity of the Total Carbohydrate Assay}

In order to optimize throughput and repeatability in carbohydrate assays, the assay was adapted to a microplate format and the linearity of the standard curves for glucose from the Total Carbohydrate Assay kit and anhydrous glucose at $2 \mathrm{mg} / \mathrm{mL}$ were tested. Figure 1(a) shows that the linearity of the standard curves for glucose from the Total Carbohydrate Assay and for the anhydrous glucose was good, with a coefficient of determination of 0.99. Comparing the standard curve for the anhydrous glucose and the glucose from the kit, both had similar linear functions, indicating good repeatability. This shows that the Total Carbohydrate Assay can result in accurate linear functions for carbohydrate content calculations. The triplicate measurements shown in Figure 1(b) also supported the repeatability and accuracy of standard curves from the Total Carbohydrate Assay with a relative standard deviation of $6.5 \%$. Overall, these results show that the Total Carbohydrate Assay is a valid alter- 

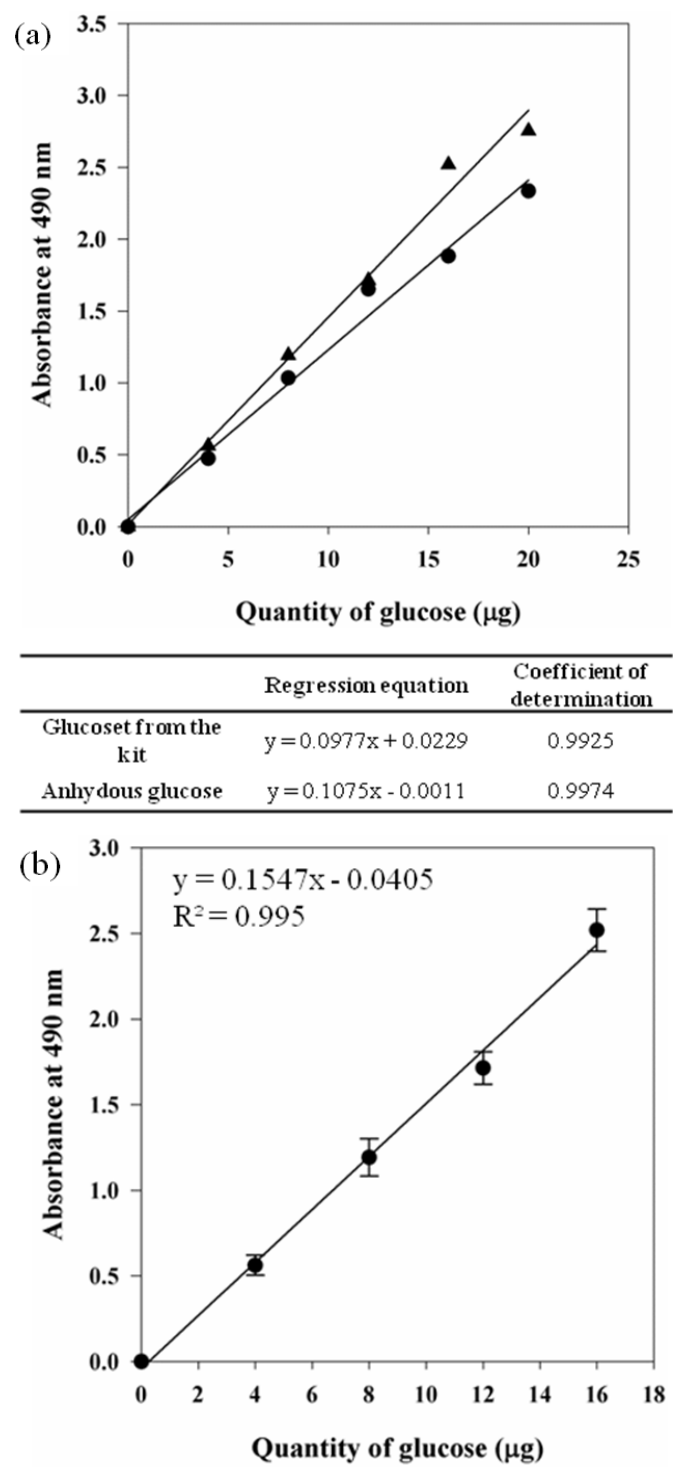

Figure 1. Linearity of the glucose standard curve. (a) Comparison of the standard curve between the glucose from the Total Carbohydrate Assay (circle) and the anhydrous glucose at $2 \mathrm{mg} / \mathrm{mL}$ (triangle); (b) Anhydrous glucose in triplicate.

native to other methods for measurements of carbohydrate content when complex glycans have to be measured in a large number of samples and commercial standards are not available. The 96-well plate format allows for rapid measurements with minimum sample volume and reagents.

\subsection{Sensitivity of the Total Carbohydrate Assay}

The protocol of the Total Carbohydrate Assay advises the use of a quantity of standard glucose ranging from 0 to $20 \mu$ g. Envisioning applications to biological samples, for which the quantities may be limited, we optimized the assays to detect even lower quantities of carbohydrate.
A satisfactory linearity was obtained for 0 to $10 \mu \mathrm{g}$ and for 0 to $5 \mu \mathrm{g}$, with coefficient of determination of 0.99 (Table 1). This indicates that the assay can detect low concentrations of carbohydrates with good sensitivity, meaning that the method can easily economize the use of samples while still obtaining accurate data on carbohydrate content.

\subsection{Effect of the Incubation Time in the Microplate Reader}

To further optimize the Total Carbohydrate Assay, the absorbance was also measured at different times of the incubation at $22^{\circ} \mathrm{C}$ in the microplate reader. Table 1 reveals that the coefficient of determination increased with incubation time in the microplate reader. The linearity of the different ranges of standard glucose tested improved starting at 20 min of incubation. A 20-min incubation allow enough time for the reaction to stabilize, allowing for more accurate spectrophotometric measurements.

\subsection{Calibration Curves of Different Monosaccharides}

Four standard curves were obtained for the monosaccharides D-glucose, D-mannose, D-galactose and L-fucose. These monosaccharides represent the building blocks most commonly found in milk oligosaccharides and glycoproteins (Figure 2). The results reveal that standard curves of the monosaccharides behave differently because each monosaccharide has a different wavelength of the maximum absorbance [14]. Technically, in order to accurately measure the carbohydrate content in biological samples using the Total Carbohydrate Assay, each sample should be compared to a curve obtained with a commercial standard. Another possibility is to create a standard curve for a sample that has a similar composition to the samples being tested.

\subsection{Quantification of Carbohydrate in Dairy-Functional Products}

Using the data described above, the Total Carbohydrate Assay was used for two bovine milk products (namely product 1 and product 2), which contained BMOs, and one sample of purified human lactoferrin, which carried complex $N$-glycans. Glucose was chosen as the reference and a glucose standard curve was used to calculate total carbohydrate content. Standard curves were also produced for bovine milk product 1 and 2 (Figure 3). A good linearity was observed for the standard curve of each product. Table 2 shows that the carbohydrate content in bovine milk product 1 and 2 was $23.38 \%$ and 32.81\%, respectively. Bovine milk contains lactose, monosaccharides (glucose and galactose) and oligosaccharides. Monosaccharides and lactose were quantified in the bovine 
Table 1. Influence of the incubation time in the microplate reader and the quantity range of analysis on the linearity.

\begin{tabular}{|c|c|c|c|}
\hline Range ( $\mu g)$ & $\begin{array}{l}\text { Time } \\
\text { (min) }\end{array}$ & $\begin{array}{c}\text { Regression } \\
\text { equation }\end{array}$ & $\begin{array}{l}\text { Coefficient of } \\
\text { determination }\end{array}$ \\
\hline \multirow{5}{*}{$0-20$} & 10 & $y=0.0839 x+0.0841$ & 0.9681 \\
\hline & 15 & $y=0.1108 x+0.0161$ & 0.9974 \\
\hline & 20 & $y=0.1393 x-0.0058$ & 0.9984 \\
\hline & 25 & $y=0.1549 x+0.0068$ & 0.9983 \\
\hline & 30 & $y=0.1629 x+0.0276$ & 0.9973 \\
\hline Range ( $\mu g)$ & $\begin{array}{l}\text { Time } \\
\text { (min) }\end{array}$ & $\begin{array}{c}\text { Regression } \\
\text { equation }\end{array}$ & $\begin{array}{l}\text { Coefficient of } \\
\text { determination }\end{array}$ \\
\hline \multirow{5}{*}{0 - 10} & 10 & $y=0.0798 x+0.0841$ & 0.9768 \\
\hline & 15 & $y=0.1026 x+0.0405$ & 0.9873 \\
\hline & 20 & $y=0.1232 x-0.0452$ & 0.9905 \\
\hline & 25 & $y=0.1422 x+0.0488$ & 0.9927 \\
\hline & 30 & $y=0.1565 x+0.0477$ & 0.9943 \\
\hline $\begin{array}{c}\text { Range } \\
\text { ( } \mu \mathrm{g})\end{array}$ & $\begin{array}{l}\text { Time } \\
\text { (min) }\end{array}$ & $\begin{array}{c}\text { Regression } \\
\text { equation }\end{array}$ & $\begin{array}{l}\text { Coefficient of } \\
\text { determination }\end{array}$ \\
\hline \multirow{5}{*}{$0-5$} & 10 & $y=0.0614 x+0.0268$ & 0.9020 \\
\hline & 15 & $y=0.1045 x+0.0126$ & 0.9895 \\
\hline & 20 & $y=0.1220 x+0.0199$ & 0.9904 \\
\hline & 25 & $y=0.1442 x+0.0166$ & 0.9932 \\
\hline & 30 & $y=0.1510 x+0.0275$ & 0.9921 \\
\hline
\end{tabular}

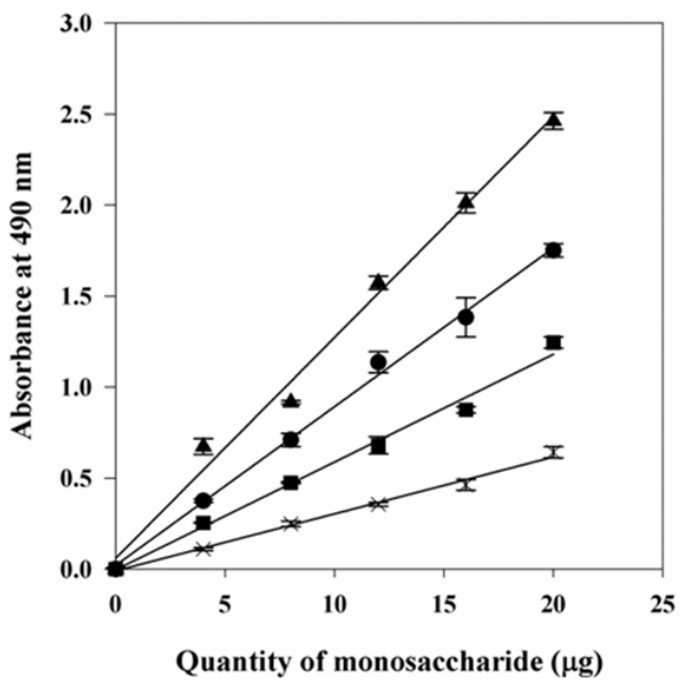

(a)

\begin{tabular}{ccc}
\hline & Regression equation & $\begin{array}{c}\text { Coefficient of } \\
\text { determination }\end{array}$ \\
\hline Glucose & $\mathrm{y}=0.1213 \mathrm{x}+0.0596$ & 0.9911 \\
Mannose & $\mathrm{y}=0.0872 \mathrm{x}+0.0207$ & 0.9969 \\
Galactose & $\mathrm{y}=0.0592 \mathrm{x}-0.0040$ & 0.9899 \\
Fucose & $\mathrm{y}=0.0313 \mathrm{x}-0.0092$ & 0.9937 \\
\hline
\end{tabular}

(b)

Figure 2. Calibration curves of four monosaccharides. (a) Standards curves: D-glucose (triangle), D-mannose (circle), D-galactose (square) and L-fucose (cross); (b) Linearity of the curves.

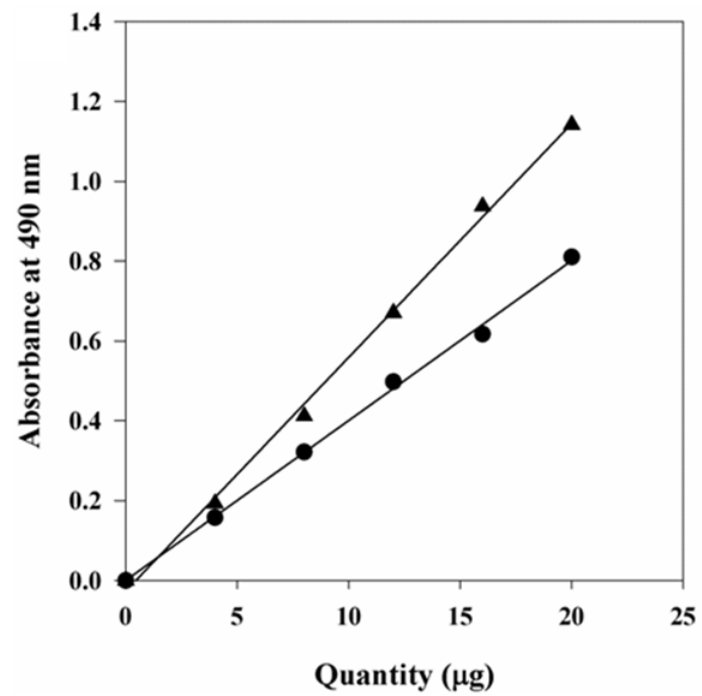

(a)

\begin{tabular}{lcc}
\hline & $\begin{array}{c}\text { Regression } \\
\text { equation }\end{array}$ & $\begin{array}{c}\text { Coefficient of } \\
\text { determination }\end{array}$ \\
\hline Bovine milk product 1 & $\mathrm{y}=0.0400 \mathrm{x}-0.0067$ & 0.9979 \\
Bovine milk product 2 & $\mathrm{y}=0.0586 \mathrm{x}-0.0226$ & 0.9973 \\
\hline
\end{tabular}

(b)

Figure 3. Calibration curves of two bovine milk products. (a) Standards curves: bovine milk product 1 (circle), bovine milk product 2 (triangle); (b) Linearity of the curves.

Table 2. Determination of the carbohydrate concentration in milk derived products, $n=3$.

\begin{tabular}{cccc}
\hline & $\begin{array}{c}\text { Total } \\
\text { carbohydrate } \\
\text { content (w/w) }\end{array}$ & $\begin{array}{c}\text { Lactose } \\
\text { content } \\
(\mathbf{w} / \mathbf{w})\end{array}$ & $\begin{array}{c}\text { Glucose and } \\
\text { galactose } \\
\text { content (w/w) }\end{array}$ \\
\hline $\begin{array}{c}\text { Bovine milk } \\
\text { product 1 }\end{array}$ & $23.38 \%$ & $\mathrm{ND}$ & $\mathrm{ND}$ \\
$\begin{array}{c}\text { Bovine milk } \\
\text { product 2 } \\
\text { Human }\end{array}$ & $32.81 \%$ & $0.019 \%$ & $\mathrm{ND}$ \\
lactoferrin & $43.21 \%$ & - & - \\
\hline
\end{tabular}

milk products. HPLC was used to determine the glucose and galactose content, and lactose was quantified by an enzymatic kit. BMOs were not quantified by HPLC because they are not separated by this method, especially with an isocratic mobile phase. The data revealed that the bovine milk product 1 and 2 did not contain free glucose or galactose. Lactose was not detected in the bovine milk product 1 and $0.019 \%$ lactose was quantified in the bovine milk product 2 . These results indicated that the bovine milk products essentially contained only BMOs. The composition of oligosaccharides in these products was investigated by nano-HPLC-Chip Q-TOF/MS after purification via solid-phase extraction. The Nano-LC coupled with the mass spectrometer provided the mass accuracy, reproducible retention times and isomer sepa- 
ration necessary for identification of the individual structures of oligosaccharides and determination of their relative abundance. The base peak chromatogram revealed two different profiles for the products (Figure 1S). Neutral and acidic BMOs were present in bovine milk product 1 and 2 but their relative abundances were different (Table 3, Table 1S). Whereas $66.37 \%$ of the total BMO abundance was neutral in the milk product 2, only $0.37 \%$ of the total BMOs abundance corresponded to neutral compounds in the milk product 1 . The abundance of acidic BMOs was higher in milk product 1 than in milk product 2, being $99.63 \%$ and $33.63 \%$, respectively. These results could explain the different carbohydrate contents obtained with the Total Carbohydrate Assay. Sialic acids have a low response factor for colorimetric methods such as the Total Carbohydrate Assay and the phenol sulfuric acid method [14]. In bovine milk product 1 , mass spectrometry showed that the relative abundance of acidic BMOs was higher than that of neutral BMOs. It could explain why the content of BMOs in product 1 obtained with Total Carbohydrate Assay was lower than that in product 2 .

A content over $43 \%$ of carbohydrates was determined for the human milk lactoferrin sample. This result shows that the kit can detect the different complex $N$-glycans attached to the protein. Different $\mathrm{N}$-glycan compositions have been previously identified, including high mannose, hybrid and complex $N$-glycan types [12,15]. Lactoferrin exhibits an array of biological activities [16-19], which are modulated by both the polypeptide chain and its glycosylated moiety [12].

These data show that the optimized Total Carbohydrate Assay is an effective assay for quantifying carbohydrates in complex biological products. Optimized conditions used in this study can be applied to further research investigating the distribution of bioactive compounds containing glycans from human and ruminant milk.

\section{Conclusions}

Because complex glycans play important structural and biochemical roles, the ability to rapidly detect and quantify these functional molecules has ample potential. Currently, there are limited quantitative data on the oligosaccharides in animal milk because current methods rely on the use of commercial standards, and commercial standards do not yet exist for several of those oligosaccharides. Even though this Total Carbohydrate Assay may underestimate the amount of acidic oligosaccharides in complex food and biological samples, the response factor of acidic oligosaccharides will stay constant. The development of an efficient and accurate colorimetric technique that only requires a compact and easy microplate reader, can help in many stages of research and can be useful for food industries. In this work, an optimized version of a carbohydrate assay was used to determine Table 3. Relative abundance in $\%$ of the neutral and acidic BMOs present in the bovine milk product.

\begin{tabular}{ccc}
\hline & Bovine milk product 1 & Bovine milk product 2 \\
\hline Neutral BMOs & 0.37 & 66.37 \\
Acidic BMOs & 99.63 & 33.63 \\
\hline
\end{tabular}

the amount of complex glycans in dairy developmental products. The various experimental conditions optimized in the present study are not limited to milk research and can be applied to a variety of agricultural or biomedical research areas. The application of this simple optimized technique can be helpful to a wide range of scientists to perform faster quality control and achieve considerable cost savings.

This method will be a valuable addition to the tool-set of food companies attempting to measure the content of functional glycans in their products. Additionally, this optimized assay will prove valuable in monitoring oligosaccharide enrichment during process development and also can be used to alert producers of potential unintended losses in oligosaccharides or glycans due to harsh processing conditions.

\section{Acknowledgements}

The authors thank C. J. Dillard for critical reading of the manuscript and Agilent Technology for assistance with the instrumentation. The authors acknowledge the technical assistance of M. Wang. The authors acknowledge support from the UC Davis Peter J. Shields Endowed Chair in Dairy Food Science.

\section{REFERENCES}

[1] G. V. Coppa, O. Gabrielli, P. Pierani, C. Catassi, A. Carlucci and P. L Giorgi, "Changes in Carbohydrate Composition in Human Milk over 4 Months of Lactation," Pediatrics, Vol. 91, No. 3, 1993, pp. 637-641.

[2] C. Kunz, S. Rudloff, W. Baier, N. Klein and S. Strobel, "Oligosaccharides in Human Milk: Structural, Functional, and Metabolic Aspects," Annual Review of Nutrition, Vol. 20, No. 1, 2000, pp. 699-722.

http://dx.doi.org/10.1146/annurev.nutr.20.1.699

[3] B. Liu and D. S. Newburg, "Human Milk Glycoproteins Protect Infants Against Human Pathogens,” Breastfeeding Medicine, Vol. 8, No. 4, 2013, pp. 354-362. http://dx.doi.org/10.1089/bfm.2013.0016

[4] R. G. LoCascio, M. R. Ninonuevo, S. L. Freeman, D. A. Sela, R. Grimm, C. B. Lebrilla, D. A. Mills and J. B. German, "Glycoprofiling of Bifidobacterial Consumption of Human Milk Oligosaccharides Demonstrates Strain Specific, Preferential Consumption of Small Chain Glycans Secreted in Early Human Lactation," Journal of Agricultural Food Chemistry, Vol. 55, No. 22, 2007, pp. 89148919. http://dx.doi.org/10.1021/jf0710480 
[5] S. Thurl, M. Munzert, J. Henker, G. Boehm, B. MullerWerner, J. Jelinek and B. Stahl, "Variation of Human Milk Oligosaccharides in Relation to Milk Groups and Lactational Periods," The British Journal of Nutrition, Vol. 104, No. 9, 2010, pp. 1261-1271. http://dx.doi.org/10.1017/S0007114510002072

[6] S. Asakuma, T. Urashima, M. Akahori, H. Obayashi, T. Nakamura, K. Kimura, Y. Watanabe, I. Arai and Y. Sanai, "Variation of Major Neutral Oligosaccharides Levels in Human Colostrums," European Journal of Clinical Nutrition, Vol. 62, No. 4, 2007, pp. 488-494. http://dx.doi.org/10.1038/sj.ejcn.1602738

[7] C. Kunz, S. Rudloff, A. Hintelmann, G. Pohlentz and H. Egge, "High-pH Anion-Exchange Chromatography with Pulsed Amperometric Detection and Molar Response Factors of Human Milk Oligosaccharides,” Journal of Chromatography B, Biomedical Sciences and Applications, Vol. 685, No. 2, 1996, pp. 211-221. http://dx.doi.org/10.1016/S0378-4347(96)00181-8

[8] S. Thurl, B. Müller-Werner and G. Sawatzki, "Quantification of Individual Oligosaccharide Compounds from Human Milk Using High-pH Anion-Exchange Chromatography," Analytical Biochemistry, Vol. 235, No. 2, 1996, pp. 202-206. http://dx.doi.org/10.1006/abio.1996.0113

[9] M. Dubois, K. Gilles, J. K. Hamilton, P. A. Rebers and F. Smith, "A Colorimetric Method for the Determination of Sugars,” Nature, Vol. 168, No. 4265, 1951, pp. 167-167. http://dx.doi.org/10.1038/168167a0

[10] A. Laurentin and C. A. Edwards, “A Microtiter Modification of the Anthrone-Sulfuric Acid Colorimetric Assay for Glucose-Based Carbohydrates," Analytical Biochemistry, Vol. 315, No. 1, 2003, pp. 143-145. http://dx.doi.org/10.1016/S0003-2697(02)00704-2

[11] M. Monsigny, C. Petit and A.-C. Roche, "Colorimetric Determination of Neutral Sugars by a Resorcinol Sulfuric Acid Micromethod," Analytical Biochemistry, Vol. 175, No. 2, 1988, pp. 525-530. http://dx.doi.org/10.1016/0003-2697(88)90578-7

[12] M. Barboza, J. Pinzon, S. Wickramasinghe, J. W. Froehlich, I. Moeller, J. T. Smilowitz, L. R. Ruhaak, J. Huang, B. Lönnerdal and J. B. German, "Glycosylation of Hu- man Milk Lactoferrin Exhibits Dynamic Changes during Early Lactation Enhancing Its Role in Pathogenic Bacteria-Host Interactions," Molecular and Cellular Proteomics, Vol. 11, No. 6, 2012, Article ID: 015248. http://dx.doi.org/10.1074/mcp.M111.015248

[13] D. L. Aldredge, M. R. Geronimo, S. Hua, C. C. Nwosu, C. B. Lebrilla and D. Barile, "Annotation and Structural Elucidation of Bovine Milk Oligosaccharides and Determination of Novel Fucosylated Structures,” Glycobiology, Vol. 23, No. 6, 2013, pp. 664-676. http://dx.doi.org/10.1093/glycob/cwt007

[14] T. Masuko, A. Minami, N. Iwasaki, T. Majima, S.-I. Nishimura and Y. C. Lee, "Carbohydrate Analysis by a Phenol-Sulfuric Acid Method in Microplate Format,” Analytical Biochemistry, Vol. 339, No. 1, 2005, pp. 69-72. http://dx.doi.org/10.1016/j.ab.2004.12.001

[15] C. C. Nwosu, D. L. Aldredge, H. Lee, L. A. Lerno, A. M. Zivkovic, J. B. German and C. B Lebrilla, "Comparison of the Human and Bovine Milk N-Glycome via HighPerformance Microfluidic Chip Liquid Chromatography and Tandem Mass Spectrometry," Journal of Proteome Research, Vol. 11, No. 5, 2012, pp. 2912-2924. http://dx.doi.org/10.1021/pr300008u

[16] N. Orsi, "The Antimicrobial Activity of Lactoferrin: Current Status and Perspectives,” Biometals, Vol. 17, No. 3, 2004, pp. 189-196. http://dx.doi.org/10.1023/B:BIOM.0000027691.86757.e2

[17] L. Seganti, A. M. Di Biase, M. Marchetti, A. Pietrantoni, A. Tinari and F. Superti, "Antiviral Activity of Lactoferrin towards Naked Viruses,” Biometals, Vol. 17, No. 3, 2004, pp. 295-299. http://dx.doi.org/10.1023/B:BIOM.0000027708.27142.bc

[18] D. Legrand, E. Elass, M. Carpentier and J. Mazurier, "Lactoferrin: Lactoferrin: A Modulator of Immune and Inflammatory Responses," Cellular and Molecular Life Sciences, Vol. 62, No. 22, 2005, pp. 2549-2559. http://dx.doi.org/10.1007/s00018-005-5370-2

[19] B. Lönnerdal, "Nutritional and Physiologic Significance of Human Milk Proteins," The American Journal of Clinical Nutrition, Vol. 77, No. 6, 2003, pp. 1537S1543S. 


\section{Supplemental Data}

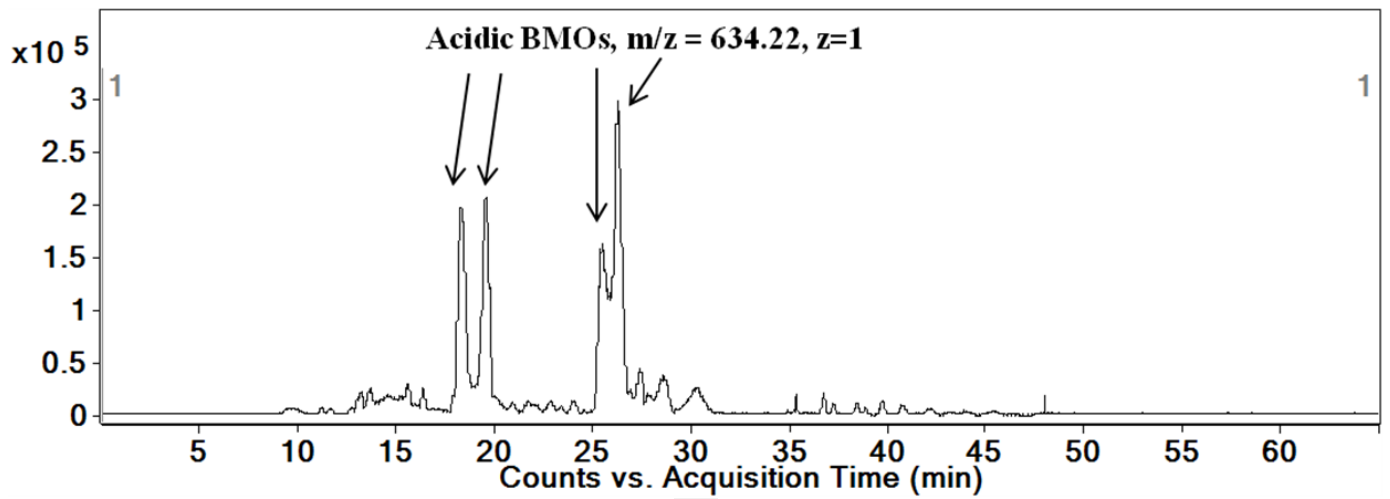

(A)

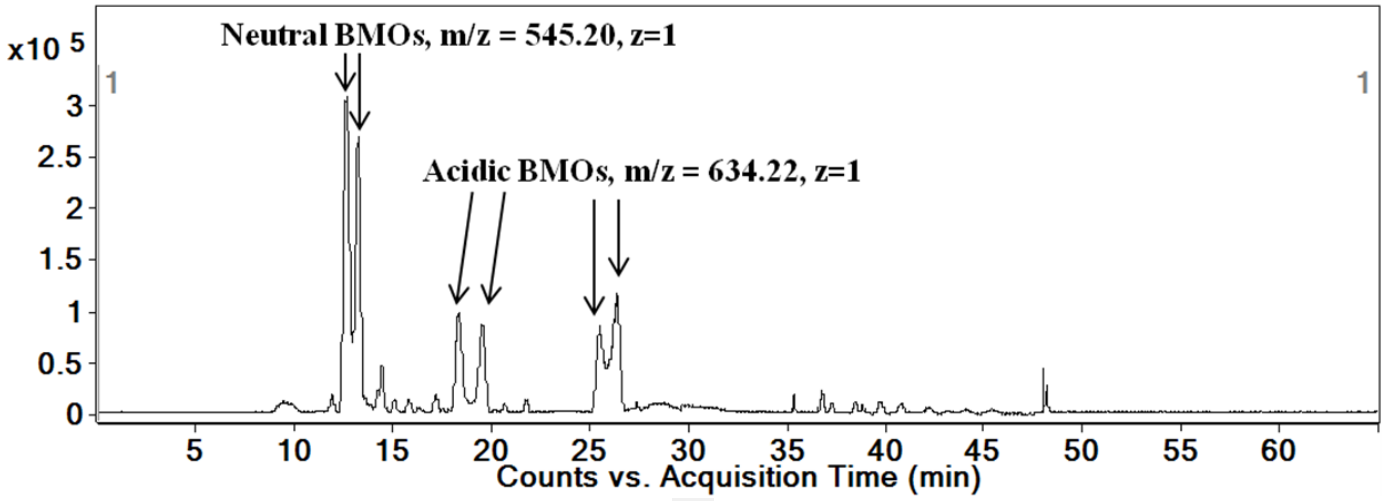

(B)

Figure 1S. Analysis of the bovine milk product 1 and 2 by Nano-LC-Chip Q-TOF/MS. (A) Base peak chromatogram of the bovine milk product 1; (B) Base peak chromatogram of the bovine milk product 2.

Table 1S. Identification of the BMOs present in the bovine milk sample 1 and 2 and determination of their relative abundance.

\begin{tabular}{|c|c|c|c|c|c|c|c|c|c|}
\hline \multirow[b]{2}{*}{$\begin{array}{c}\text { Neutral } \\
\text { mass }\end{array}$} & \multicolumn{8}{|c|}{ Composition } & \multirow[b]{2}{*}{$\begin{array}{c}\text { Relative abundance } \\
\text { in bovine milk } \\
\text { product } 2(\%)\end{array}$} \\
\hline & $\mathbf{m} / \mathbf{z}$ & $\mathbf{z}$ & Hexose & $N$-acetylglucosamine & Fucose & $\begin{array}{c}N \text {-acetyl } \\
\text { neuraminic } \\
\text { acid }\end{array}$ & $\begin{array}{l}N \text {-glycolyl } \\
\text { neuraminic } \\
\text { acid }\end{array}$ & $\begin{array}{l}\text { Relative abundance } \\
\text { in bovine milk } \\
\text { product } 1(\%)\end{array}$ & \\
\hline 504.17 & 505.18 & 1 & 3 & 0 & 0 & 0 & 0 & ND & 7.42 \\
\hline 545.20 & 546.20 & 1 & 2 & 1 & 0 & 0 & 0 & ND & 50.45 \\
\hline 707.25 & 708.26 & 1 & 3 & 1 & 0 & 0 & 0 & ND & 4.38 \\
\hline 748.27 & 749.28 & 1 & 2 & 2 & 0 & 0 & 0 & ND & 0.86 \\
\hline 869.30 & 870.31 & 1 & 4 & 1 & 0 & 0 & 0 & 0.37 & 1.48 \\
\hline 910.33 & 911.34 & 1 & 3 & 2 & 0 & 0 & 0 & ND & 1.78 \\
\hline 633.21 & 634.22 & 1 & 2 & 0 & 0 & 1 & 0 & 74.51 & 31.76 \\
\hline 649.21 & 650.21 & 1 & 2 & 0 & 0 & 0 & 1 & ND & ND \\
\hline 674.24 & 675.25 & 1 & 1 & 1 & 0 & 1 & 0 & 6.31 & 0.45 \\
\hline 795.26 & 796.27 & 1 & 3 & 0 & 0 & 1 & 0 & 8.26 & 1.41 \\
\hline 811.26 & 812.27 & 1 & 3 & 0 & 0 & 0 & 1 & ND & ND \\
\hline 836.29 & 837.30 & 1 & 2 & 1 & 0 & 1 & 0 & 0.90 & ND \\
\hline 924.31 & 925.31 & 1 & 2 & 0 & 0 & 2 & 0 & 9.66 & ND \\
\hline
\end{tabular}

